CIC. Cuadernos de Información y Comunicación ISSN: 1135-7791

http://dx.doi.org/10.5209/CIYC.55953

\title{
El supuesto digital: 10 tesis $^{1}$
}

\author{
Ippolita $^{2}$; Geert Lovink ${ }^{3}$; Ned Rossiter ${ }^{4}$
}

Propuesto: 3 de enero de 2017 / Aceptado: 10 de enero de 2017

Resumen. Como hiciera con el fenómeno Wikileaks, Lovink y sus colegas nos presentan diez tesis fundamentales que forman la base de diversas argumentaciones en torno a los ya establecidos medios digitales, discutiendo su importancia y su desarrollo, desde ángulos críticos y polémicos, analizando las dimensiones ocultas del mundo digital así como el potencial no desarrollado de posibilidades políticas y sociales que aparecen con ellos.

Palabras clave: Nuevos medios; web 2.0; crítica; manipulación; estructura comercial.

\section{[en] The digital given: 10 Theses}

\begin{abstract}
As he developed precedently with the phenomenon of Wikileaks professor Lovink and their colleagues present us 10 fundamental thesis about the new digital media, discussing their importance and the features of their progress, from a critical and polemical perspective, analyzing the hidden aspects as well as the potential undeveloped of socio-political possibilities that were implied in them.
\end{abstract}

Keywords: New media; web 2.0.; critic; manipulation; commertial structure.

Cómo citar: Ippolita; Lovink, G.; Rossiter, N. (2017). El supuesto digital: 10 tesis, en CIC. Cuadernos de Información y Comunicación 22, 13-18.

1 Traducción de Eva Aladro. Este artículo se publicó originalmente en una lista de distribución, Nettime, y en los blogs de sus autores. Agradecemos a Ippolita, Geert Lovink y a Ned Rossiter la publicación de algunos textos seleccionados, en los que se plantean temas cruciales de la cultura digital que añadir a los planteados en en número sobre Web 2.0 de la afamada publicación Fibreculture Journal.

2 Italia. Ippolita es un colectivo italiano interesado en todas las cuestiones de la nueva cultura digital.

3 University of Amsterdam. Geert Lovink es Profesor Investigador sobre Medios Interactivos en la Hogeschool van Amsterdam (HvA) y Associate Professor sobre Nuevos Medios en la Universidad de Amsterdam (UvA). Lovink es fundador del Institute of Network Cultures, cuyo objetivo es explorar, documentar y auspiciar el potencial socio-económico de los nuevos medios mediante el diálogo abierto, el trabajo de campo y la organización de eventos. Es autor de libros tan importantes como Dark Fiber, Uncanny Networks, My First Recession and Zero Comments: Blogging and Critical Internet Studies.

4 University of Nottingham, Ningbo. Ned Rossiter es Associate Professor en Culturas en Red de la University of Nottingham, y de Ningbo, China, así como Adjunct Senior Research Fellow en el Centre for Cultural Research de la Universidad de Western Sydney, en Australia. Autor de los libros Organized Networks: Media Theory, Creative Labour, New Institutions (2006) y co-editor de numerosos colúmenes, como (con Geert Lovink) MyCreativity Reader: A Critique of Creative Industries (2007). 
0.

Internet ha resultado no ser ni el problema ni la solución en la recesión global. Como un espectador indiferente, no se presta fácilmente a ser una herramienta revolucionaria. Lo virtual se ha convertido en rutinario. El nuevo mundo se nos presenta como verde, no como digital. Lo digital se presupone. Esta posición humilde plantea la oportunidad de repensar la fama de la web 2.0. ¿Cómo debemos conceptuar nuestra implicación política, emocional y social en la cultura de la red para los próximos años?

\section{1.}

Los medios de información no hablan más que de "crisis económica", y se revuelcan en el espectáculo generado por ellos mismos de catástrofe nuclear financiera. Los expertos están movilizados, pero solo para generar un drama de disensos. El descontento programado es el consenso de todos los medios informativos diarios. La crisis, después de todo, es la precondición básica del capitalismo. A diferencia de la catástrofe de las punto.com ocurrida entre 2000 y 20012, cuando el colapso de las acciones en altas tecnologías alimentó la recesión global, Internet ha conseguido hasta ahora mantenerse al margen del juego de acusaciones. La web 2.0 sufre tan sólo efectos colaterales suaves en su extraña colección de plataformas y servicios, de Google a Wikipedia, Photobucket, Craigslist, MySpace, Facebook, Twitter, Habbo y los llamados jugadores regionales como Baidu y 51.com. A pesar de su benigna existencia, hay hipertrofia mires donde mires. Las plataformas y las aplicaciones 2.0 siguen siendo "nuevas" aunque muestran una tendencia a perderse dentro de las vidas aburridas, estresadas e inciertas de los billones de personas conectadas.

\section{2.}

Las redes sociales son tecnologías del entretenimiento y la difusión. La realidad social que crean es real, pero como tecnología de la inmediatez debe producir necesariamente una satisfacción. Inicialmente nos entusiasmaron porque nos distraían de la tortura del tiempo actual. Las redes son drogas sociales para aquellos que necesitan al Humano que está ubicado en alguna otra parte del tiempo o del espacio. Con quien conectamos es con el pseudo-Otro mediante las mismas. No es el Otro significativo ni es el Otro real. Sistemáticamente exploramos la debilidad y la vaguedad y nos vemos presionados para llevar aún más allá la exhibición del Yo. "Puede que te conozca (pero no). ¿Te importa conocerme?" El principio del placer del entretenimiento diluye así los antagonismos sociales - ¿cómo se manifiesta el conflicto dentro de las zonas de confort de las redes sociales y en sus labores primorosas de la auto-personalización? La "doctrina de la confianza" del modelo empresarial ha eliminado del todo los foros abiertos y sucios de Internet. La mayoría de la web 2.0, viene constituida por cámaras de eco de las mismas viejas opiniones y patrones culturales de siempre. Como todos podemos atestiguar, no son canteras exactamente de subculturas alternativas. Lo que es nuevo son sus cualidades "sociales": la red es el mensaje. 
Lo que se ha creado en ellas es un sentido de aproximación a lo social. Las redes sociales registran un "rechazo al trabajo". Pero nuestro tiempo en la red, después de todo, es un tipo específico de rendimiento laboral. En esto radica la perversidad de las redes sociales: por radicales que sean, siempre pueden usarse para la minería de datos. Han sido diseñadas para ser explotadas. El rechazo a una filosofía de trabajo se convierte en otra forma de hacer dinero que no es vista nunca por nuestros ojos.

\section{3.}

Los sitios de las redes son víctimas de la moda más que ninguna otra cosa. Llegan y se van. Sus migraciones en el espacio marcan la enculturización del software. Mientras Orkut ha desaparecido de los países del G8, todavía es grande en Brasil. ¿Hay realmente todavía gente invirtiendo en propiedades inmobiliarias en SecondLife? Lo que el mundo digital necesita son relaciones sociales sostenibles. Los rebaños migrantes que van de un servidor al otro simplemente demuestran una mentalidad impulsiva de ganado: una vez instalan los complementos más modernos, es hora de mudarse. La sostenibilidad está conectada con la escalabilidad. Aquí tenemos lecciones que tomar de los principales movimientos sociales de los últimos 50 años. La fuerza de los deseos político-sociales acumulados se manifiesta, al final, en fórums globales y nacionales que se traspasan a los discursos políticos y las prácticas sociales: pensemos en la marcha sobre Washington de 1963 (Derechos Civiles para los Negros) de Rio en 1992 (Cumbre de la Tierra), Porto Alegre en 2001 (Foro Social Mundial), los sucesos en Ginebra y Túnez de 2003-2005 (Cumbre Mundial sobre la Sociedad de la Información). Ninguno de estos ejemplos están exentos de crítica. Notamos que marcan la relación entre sostenibilidad y transformación escalar. Están relacionados con formatos como las acampadas, las conferencias externas y los talleres con tecnologías de elaboración propia; hemos participado en alguno de esos festivales de artes y medios de temporada. Pero difícilmente alguno de ellos puede considerarse una acción sostenible. La temporalidad de su jueguecito viene gobernada por la duración del evento. Es verdad que ocasionalmente hay resonancia en los laboratorios mediáticos locales, pero esas prácticas se hacen exclusivas de las sociedades secretas tecnocráticas, y no de las masas en red. Los sitios web de las redes son notables por su capacidad escalar. Su debilidad es la incapacidad patente para llevar a cabo un cambio político efectivo de ningún modo sustantivo. El valor que podamos darle al periodismo ciudadano nada tiene que ver con la intervención radical, y más bien se entiende como un síntoma estructural de la lógica estructural de generar financiación externa para la producción mediática y de gestión de campañas electorales.

\section{4.}

De lo social al socialismo hay un pequeño paso para la Humanidad y un gran paso para el sujeto occidental. ¿Qué convierte a lo social en algo tan atractivo, y a lo socialista en tan viejo y aburrido? ¿Qué es lo social, después de todo? Tenemos que darnos cuenta de que estos juegos del lenguaje académico postmoderno no profundizan nuestra comprensión de los temas, ni amplían nuestras fantasías políticas. Necesita- 
mos imaginación, pero solamente si ésta ilumina conceptos que transformen condiciones concretas. La resurrección de lo social tras su desaparición no es un eslogan atractivo. Algunas ideas tienen casi un acceso directo a nuestro cuerpo. Otras siguen muertas. Esto es muy importante para parte de la jerga militante como ocurre con las palabras renta, multitudes, común, comunal, o comunismo. Hay aquí una compulsión hacia la auto-referencia que no es muy distinta al defecto narcisista de tantos y tantos blogs. ¿Cuáles son, pues, los conceptos colectivos de las masas de integrantes de las redes? De momento, los conceptos los fabrican los programadores de alta gama de las empresas, o bien provienen del mundo de las aplicaciones informáticas. Etiqueta, Conectado, Amigo, Enlace, Comparte, Tuitea. No son términos que señalen ningún tipo de inteligencia colectiva, de creatividad o de socialismo en red. Son directrices del Comité Central del Software. "Participación", en las "redes sociales" no sirve ya, si es que alguna vez sirvió, como recipiente mágico para transformar a los individuos cansados o aburridos en miembros chulísimos de una mitológica Inteligencia Colectiva. Si tú no eres un individuo interesante, tu participación no es realmente interesante. Las nubes de datos son, después de todo, nubes: se disipan. Las mejores redes sociales se organizan gracias a contar con mejores individuos, es tu responsabilidad, te toca a ti. Lo que necesitamos es una invención de software de red social en la que todo el mundo se convierte en diseñador conceptual. ¡Activemos el click y demos paso a miles de millones de pequeños juguetones!

\section{5.}

Somos adictos a los ghettos, y así rechazamos los antagonismos de "lo político". ¿Dónde está el enemigo? No en Facebook; donde solamente puedes tener "amigos": lo que la web 2.0 acusa como carencia es la técnica del lazo antagónico. En su lugar, nos vemos confrontados con la Tiranía de la Energía Positiva. La vida consiste solamente en experiencias energizantes. La depresión no es un principio de diseño. La confianza de Wikipedia en la "buena fe" y su política de protocolos a menudo produce una experiencia deprimente ante la ausencia de un estilo parcial. No hay nada que no sea un "punto de vista neutral". Este principio de diseño de software sencillamente reproduce el Sistema de Creencia Única. Los formatos deben transformarse si tienen que acomodarse a la pluralidad de expresiones de la vida en red. Los templates funcionan como zonas de exclusión. Pero también curiosamente, excluyen el conflicto de fronteras. El virus es lo más parecido al conflicto en el mundo online. Pero los virus trabajan en modos invisibles y funcionan como generadores de trabajos del servicio para el empollón del ordenador que viene a limpiártelo de virus.

\section{6.}

La crítica a los simulacros de la web no nos satisface. No hay nada "falso" en la virtualidad de las redes y sitios sociales. Son tan reales como es posible hoy en día. La estabilidad se acumula para los que están enganchados a las redes. Las cosas simplemente siguen expandiéndose. Más solicitudes. Más amigos. Más tiempo para el tiempo social. Con el cierre de las fábricas llega la apertura de las minas de datos. 
La privacidad está tan vacía de curiosidad que nos vemos forzados a estamparla en nuestro muro para que la vean todos. Si tenemos suerte, lo mismo un Amigo la rebota con un comentario. ¡Y si te sientes generoso, levántame un pulgar! Te sentirás muy presionado a manifestar tu recepción de cualquier cambio sustancial. Pero tendrás que realizar tareas de mantenimiento eternas para controlar y dirigir todos los sistemas de retroalimentación de datos y las actualizaciones de los mismos. Te quitará un poco de tiempo de tu rutina diaria.

\section{7.}

La red social no será Revolucionada. ¿Qué significa esto para Indimedia2.0? La pregunta de por qué Indimedia.org fracasó y no se desarrolló en forma de plataforma de activismo y red social hasta tomar una posición importante en el debate de la web 2,0 es un asunto que debe ser analizado (ver el debate que se planteó en mayo de 2009). ¿Han aprendido los activistas mediáticos suficiente de lo ocurrido en los últimos años de los 90 con la brechtiana obra ilustrativa de Indimedia? ¿Es hoy tan importante la marca y el diseño de imagen como en el caso de Indimedia.org (un nombre, un diseño similar, compartición de servidores, cierta sindicación de contenidos, etc). Indimedia se topó con el desafío de la escalabilidad de modo sorpresivo, para descubrir simplemente sus límites. La contaminación parece clave para las redes sociopolíticas internacionales. Tanto como las reuniones regulares cara a cara. Sin duda es muy importante que una red conecte con los procesos concretos de adaptación y transformación. Después, es necesario re-conectar entre las redes ( $\mathrm{y}$ con otras formas institucionales y organizacionales) en la escala global. El conflicto puede haberse multiplicado y la condición primaria de sostenibilidad estará fuera de alcance.

\section{8.}

La web 2.0 no es gratuita. "Libre como la entrada libre" no es "libre como la libertad". Abierto no significa libre. En estos días "libre" es simplemente otro término de servicio de las empresas. La gente de Linux lo sabe muy bien. Necesitamos poner en duda esas campañas infantiles que simplemente promueven "cultura libre" sin poner en cuestión la economía parásita que subyace a la misma y la desprofesionalización del trabajo cultural. El total cribado genético de nuestra identidad es el precio a pagar por esta apertura a los "valores del mercado libre". Como usuarios y consumidores nos vemos utilizados por nuestra capacidad como productores de datos. Nuestros gustos y preferencias, nuestras opiniones y movimientos, son el precio de mercado a pagar. Ahora mismo, el voluntario y entusiasta sistema de Facebook para generar un auto-archivo de cada usuario a escala masiva representa el punto álgido de esta estrategia. Pero no podemos sucumbir a la paranoia del control ni a la lógica del miedo. ¡Vamos a inyectar más kaos en esto! Así que ¿qué tal si creamos un grupo anti-lo que sea en Facebook? ¿Qué tal si cambiamos, en lugar de expandir el número de nuestros amigos? ¿Será el borrado la acción simbólica más radical de 2009? ¿Por qué no damos la sorpresa con alguna acción subversiva divertida, anti-cíclica? ¿Están pensando en alguna táctica rebelde de este estilo? 


\section{9.}

Pronto el modelo de negocio de la web 2.0 estará obsoleto. Se basa en el principio de crecimiento ilimitado, el crecimiento infinito del consumismo. El modelo de negocio citado sigue el necio modelo de las puntocom: si el crecimiento se estanca, significa que el negocio ha fallado y hay que cerrarlo. El crecimiento ilimitado de la publicidad adaptada al cliente es la gasolina de esta forma del capitalismo, descentralizado por el usuario-prosumidor. La polución mental del entorno es paralela a la polución medioambiental. Pero nuestro mundo se ha terminado (limitado). Tenemos que empezar a elaborar tecnologías apropiadas para un mundo finito. No hay una exterioridad, no hay otros mundos (segundo, tercero, cuarto mundo) donde podamos verter los efectos colaterales de los desarrollos demenciales. Sabemos que el Progreso es un bien sediento de sangre que precisa terribles sacrificios humanos. Un buen fin no puede justificar un mal medio. Por el contrario, las tecnologías son medios que deben justificar el fin de la libertad común. Ningún sacrificio debe ser tolerado: los mártires no son bienvenidos. Tampoco los héroes.

10.

Mejor una identidad complicada que un complejo de identidad. Necesitamos promover la educación igualitaria que cambie de una cultura por defecto de la auto-formación, al placer nihilista en piratear el sistema. La exhibición personal en las redes sociales de la web 2.0 recuerda al descubrimiento de la sexualidad. La ansiedad por la masturbación se encuentra con el narcisismo digital (el retoque obsesivo de los perfiles personales) y con el voyeurismo digital ( el visionado compulsivo de los perfiles de otros, de las listas de amigos, secretos, etc). Para evitar la doble trampa de una tecnofilia enceguecedora y de una tecnofobia ludita, debemos desarollar identidades digitales complejas. Tienen que responder a los deseos individuales y satisfacer múltiples necesidades. Las ID abiertas son un buen punto de partida. "Roba mi perfil". Es hora de remezclar la Identidad. El anonimato es una buena alternativa a las presiones de la sociedad de control, pero tiene que haber alternativas que ofrecer. Una estrategia puede ser hacer que la Identidad (la "real") sea más compleja y, si es posible, contradictoria. Pero sea como sea nuestra Identidad, que siempre sea algo en cultivo. Si debemos participar en la economía de la acumulación para los que dominan las minas de datos, por lo menos que podamos Falsificar nuestra Persona. 